\title{
Finite element analysis of sheet metal formability effect on automotive part
}

\begin{abstract}
An increasing demand for lower price and better quality vehicle has increase complexity of tool development process. This includes concept evaluation, design phase, prototype phase and pre production phase. Experience show that R\&D spends most of the time and cost for tool development process, which includes assembly tooling, product tooling for automobile sheet metal component or part requires the highest cost in tool development process as most metal stamping part requires more than one tool to produce finished stamping part. For these reason, sheet metal forming simulation and analysis at early stage of tool development process is very important to shorten the tool development cycle time and cost. In other word by applying sheet metal forming simulation and analysis at early stage it can reduce the die manufacturing cycle time and cost.
\end{abstract}

Keyword: Automotive; Drawbead; Finite element analysis; Formability effect; Sheet metal forming 